it stands against the current hijack of mental health services by a scientific reductionist 'nothing but'ism which dehumanises man and reduces agency to mechanism, presided over by a psychiatric elite complete with training and research facilities and establishment approval. The current intellectual, moral and financial bankruptcy of such an approach makes the time ripe for a humanistic psychiatry which, as Ledermann suggests, gives a central role to the conscience, that still, small voice that calls man to authenticity rather than drug-induced suppression or manipulation: that affirms his freedom to change himself.

The book falls into two parts, a larger part stating Ledermann's conceptual framework and defining the roles of conscience, authentic and inauthentic guilt described in classical, non-theistic existential terms. This part is densely written and like much existential literature, at times turgid and difficult to follow. His ethic prefers Buber's 'IThou' relationship to Sartre's 'Hell is other people'; an unacknowledged influence is John MacMurray (Persons in Relation) who explores the philosophical basis of interpersonal psychology and therapy more adequately than here. There follows a quick run-through of alternative models of mental illness and its treatment which are rejected as deterministic, oppressive and invalid; psychoanalysis, behaviour therapy, anti-psychiatry, organic psychiatry and Gestalt therapy all being disposed of.

Ledermann is much influenced by Romantic notions of the true self which must be helped to declare itself for healing to occur through the therapist's appeal to the conscience. Although not explicitly identified with a religious impulse, a Low Church Christian, such as a Quaker, would have little difficulty in agreeing with this mode of approaching 'the road to freedom'. Likewise, although he explicitly negates Jung's metapsychology of inner objects, as indeed those of Freud and later object relations theorists, Ledermann's subsequent (and disappointingly brief) description of individual therapy implies a heavy reliance on elucidating the meaning and purpose of the individual's defences and avoidances in seeking freedom and selfactualisation; and is illustrated by dreams, reveries, hypnoidal states and drawings, none of them in practice different from the material of the Jungian analyst. While he rejects a reductionist analysis of behaviour to the resultant of mental structures, his illustrations of therapy in action disclose a reliance on developmental theory and the effects of adverse early experience prior to conscious recall, particularly within families. His picture of the development of therapy emphasises how increased selfrealisation and independence follow upon the recapitulation and remaking of failed earlier experience.

A number of unexplored issues could have been developed. One aspect of therapy appears to consist of verbal analysis and imaging of conflicts through dreams, resolved by imaging other solutions. Psychodrama would seem to be a more powerful and effective extension of this approach which Ledermann does not mention. Neither does he explore the important issue of the therapist's interpretations and their validity - his examples leave the reader unclear as to who interprets what, and how to know whether or not the interpretation is correct. The work of the German philosopher Gadamer on hermeneutics would amplify his account of therapy, emphasising as it does human understanding as engagement in Sartre's sense rather than trained, methodical technique. This raises the further question of training for the existential therapist in 'guided intuition', or how to understand another human being other than through technical understanding; an issue Ledermann hints at but does not develop.

One last point - to the uninformed, the publisher and author are very coy as to where and in what setting Ledermann works. This is particularly important as the average National Health Service consultant will declare Ledermann's approach interesting but impossibly time-consuming in view of the claims on his or her attention of acute psychosis and psychopathic behaviour. These Ledermann excludes from existential therapy until in remission on similar grounds to those of the Enlightenment savants: they illustrate loss of reason and moral sense, an appeal to which is the existential therapist's main recourse. Although steering a middle course between orthodox therapies for the very ill and a radical call to freedom for the not so ill, the boundaries of and rationale for this division is inadequately explored, Ledermann being content to categorise as 'illness' what cannot be appealed to. This seems a fundamental avoidance of a central issue and threatens to undermine the applicability of his entire theoretical stance.
STEPHEN LITTLE,

Freelance Child Psychiatrist and Psychotherapist, Kent

\section{Medizinische Ethik}

F J Illhardt, Berlin/Heidelberg/New York/Tokyo, 220 pages, DM 52.00, Springer-Verlag, 1985.

This book intends giving health-care trainees an introductory presentation of the most current and important topics in medical ethics. The issues are grouped in four categories: beginning of life, lifecrises, end of life, and research. Each topic is briefly presented and discussed, with occasional reference to its medical, philosophical or sociological context. Due to the compact format of the book, some relevant ethical problems are made short work of - triage spans only one page, abortion merely two. References include a number of pertinent European and American publications, but most reputed journals and periodicals in the field are ignored. Each topic is enriched by a brief account of the Federal German legal situation, provided by $\mathrm{H} \mathrm{G}$ Koch. An addendum reproduces numerous legal texts, regulations, declarations and bills of rights.

The author's ethical stance is that patients are fundamentally autonomous but in need of help. The emphasis on helplessness, which has a strong tradition in German meta-medical writings, makes it all too easy to restrict or cancel autonomy. Illhardt in fact does so when defending resuscitation of suicidal individuals or when justifying the occasional interruption - or forced continuation - of therapy against patients' will, based on his view that patients ultimately decide 'under pressure'. To buttress his 'provisional' or situational kind of ethics, the author all too often resorts to contingent, ambiguous or even contradictory rhetoric. Thus, Illhardt condemns compulsory commitment of the mentally disabled but accepts that in certain instances - which he doesn't specify - it may be unavoidable. Abortion is rejected but reconsidered on second thoughts if extensive counselling fails. On the one hand, artificial insemination is eyed with suspicion because it disrupts the natural course of events. On the other hand, nature's course should actively be interfered with in decisions concerning resuscitation. Although he more than once employs them, the author explicitly dismisses arguments based on 
dichotomies like natural/unnatural as being 'subjective and vague' ( $p$ 110). The style becomes at times somewhat pleonastic, as when respect for 'personality and dignity of emerging life' is demanded in relation to the discussion of artificial insemination, or in the statement that getting an organ transplant means a chance to live but also the necessity of 'keeping one's identity with one's I'.

Illhardt omits certain topics and allows a few factual mistakes to mar the text. Among the neglected topics are health-care policies, medical strikes, sexual problems, confidentiality, whistle-blowing, and medical documentation. Errors include misspelling Patau, confusing P Singer with $M G$ Singer and mislabelling the Austrian writer J Amery as a French philosopher. Wrongful life is misdefined as parents' claim against medical or social institutions. Ars moriendi, an unsettling medieval forerunner of macabre themes, is mentioned as consolation literature for the dying. And the London Medical Group is not an ethics commission ( $p$ 161), but a study group which happened to be founded in the same year as the first British Research Ethics Committees.

Shortcomings aside, the book is an adequately structured and broadly focused introduction to modern medical ethics. It should prove useful to beginners in the field, provided they are not misled by the author's apparent eclecticism and the somewhat erratic selection of references. Incidentally, for a text that carried the sub-title 'a work book', this paperback seems grossly over-priced.

MICHAEL H KOTTOW Ophthalmologist, Im langen Hau 33, Stuttgart 80, FRG

\section{A code of Ethics for Social Work - the Second Step}

David Watson, editor, London, 180 pages, £5.95, BASW and Routledge and Kegan Paul, 1985.

This thoughtful and thought-provoking book deserves a wide readership because it demonstrates an attempt to redefine and review steps taken by social workers in their search for professional ethics. The nine authors contribute generously from their own experiences and thinking since the $F$ irst
Step was taken ten years ago by the adoption by the British Association of Social Workers (BASW) of a ten-point ethical code. That code is reproduced in this book.

Social work in its various forms must constitute one of the oldest bodies of worthwhile work known to civilised societies but only during the last few years have serious attempts been made to weld social workers into a profession. The ninth contributor, a doctor, draws helpful parallels between medical and social-work practice and I would have welcomed other comparative contributions from members of yet other professions, especially those where it is implicit that the practitioner is an employee and therefore, as the vast majority of social workers are, less than autonomous. Some of the writers have made their contributions clear to readers of any background by giving a few precise examples. Others have not given examples thus at times leaving the non-social-work reader, such as myself, seriously disadvantaged.

In particular I was pleased that several of the contributors had addressed the issue of whose interests social workers should pursue: the client's, or those of the social worker's employing authority. I would have liked to have seen more discussion about the possible confusion between personal values and professional objectives. Members of older professions, such as doctors and lawyers, sometimes do not realise how much their own personal or cultural values may influence how they behave towards their patients or clients. Early in my training as a psychiatrist, before abortion law reform, a senior psychiatrist pointed out to me that by ascertaining the religious persuasion of gynaecological colleagues the psychiatrist engineered whether or not his patient would be likely to be offered a termination of pregnancy!

Some readers may be disappointed that the money ethics behind some social-work decisions are not sufficiently addressed. For instance I found no mention of how it is decided in a social-work department when a child in a problem family will be removed; when work with that family is to be switched to work against that family; when efforts to rehabilitate a child will be switched to severing that child's connections with his family so that he may be fostered with a view to adoption thereby ending social work intervention in that case.

This is a readable, concise, wellproduced paperback, it is indexed and the bibliography extends over five pages. It should be of value to all

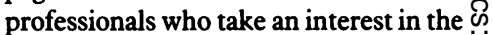
ethics of their own or any other profession, especially those professions $\stackrel{\oplus}{+}$ that operate within the gap between a음 perpetually demanding client group $\bar{\sigma}$ and an eagle-eyed management $\bar{c}$ structure. For social workers that $\overparen{\nabla}$ management structure changes its top layer, the voted members of the social os services committees, every four years.

DR R BENIANS $\overrightarrow{\vec{\omega}}$

Consultant Psychiatrist to

Ealing Child Guidance Service, 42 Madeley Rd, London W5

A Primer of Medicine

N

M H Pappworth, London, 378 pages, $£ 19.50$, Buterworth, 1984.

Modern medical textbooks are worthy tomes; sombre in style, redolent with science and written, very often, in the passive voice. Dr Pappworth is a highly individualistic practitioner and teacher of medicine, and his textbook comes as a refreshing change. The opinions and experience of the author are unambiguously stated for the student in this the fifth edition of a book first published in 1960.

The first five chapters are of particular interest for readers of this journal, covering the following topics: ethical precepts, learning and teaching clinical medicine, medical vocabulary, the art and science of diagnosis, and history-taking.

In the first chapter he summarises the various ethical codes that have been used in the last few thousand years and proposes a new code of his own with 15 main points, which range from fairly universal principles such as the need to $N$ treat patients with sympathy and care regardless of race, colour or religion, to $\mathrm{N}$ a less common one - that the doctor $N$ should 'treat doctors' wives or husbands and their children without any payment in money or kind'. Whether one agrees or disagrees with his principles, it is refreshing to see that the student will be plunged into these issues in the first chapter.

The second chapter attacks such sacred cows as basic science, research, $\mathbb{D}$ and specialisation and Dr Pappworth $\sigma$ argues that these activities and trends have been unduly influential in the last $\delta$ two decades. In his chapter on medical vocabulary he justifiably attacks neologisms, jargon, and abbreviations, 